\title{
Integrating proteomic and phosphoproteomic data for pathway analysis in breast cancer
}

Jie Ren, Bo Wang and Jing Li ${ }^{*}$

From The International Conference on Intelligent Biology and Medicine (ICIBM) 2018

Los Angeles, CA, USA. 10-12 June 2018

\begin{abstract}
Background: As protein is the basic unit of cell function and biological pathway, shotgun proteomics, the largescale analysis of proteins, is contributing greatly to our understanding of disease mechanisms. Proteomics study could detect the changes of both protein expression and modification. With the releases of large-scale cancer proteome studies, how to integrate acquired proteomic and phosphoproteomic data in more comprehensive pathway analysis becomes implemented, but remains challenging. Integrative pathway analysis at proteome level provides a systematic insight into the signaling network adaptations in the development of cancer.

Results: Here we integrated proteomic and phosphoproteomic data to perform pathway prioritization in breast cancer. We manually collected and curated breast cancer well-known related pathways from the literature as target pathways (TPs) or positive control in method evaluation. Three different strategies including Hypergeometric test based over-representation analysis, Kolmogorov-Smirnov (K-S) test based gene set analysis and topology-based pathway analysis, were applied and evaluated in integrating protein expression and phosphorylation. In comparison, we also assessed the ranking performance of the strategy using information of protein expression or protein phosphorylation individually. Target pathways were ranked more top with the data integration than using the information from proteomic or phosphoproteomic data individually. In the comparisons of pathway analysis strategies, topology-based method outperformed than the others. The subtypes of breast cancer, which consist of Luminal A, Luminal B, Basal and HER2-enriched, vary greatly in prognosis and require distinct treatment. Therefore we applied topology-based pathway analysis with integrating protein expression and phosphorylation profiles on four subtypes of breast cancer. The results showed that TPs were enriched in all subtypes but their ranks were significantly different among the subtypes. For instance, p53 pathway ranked top in the Basal-like breast cancer subtype, but not in HER2-enriched type. The rank of Focal adhesion pathway was more top in HER2- subtypes than in HER2+ subtypes. The results were consistent with some previous researches.
\end{abstract}

Conclusions: The results demonstrate that the network topology-based method is more powerful by integrating proteomic and phosphoproteomic in pathway analysis of proteomics study. This integrative strategy can also be used to rank the specific pathways for the disease subtypes.

Keywords: Proteomics, Phosphoproteomics, Integration, Pathway analysis, Breast cancer

\footnotetext{
* Correspondence: jing.li@sjtu.edu.cn

Department of Bioinformatics and Biostatistics, School of Life Sciences and

Biotechnology, Shanghai Jiao Tong University, Shanghai 200240, China
}

(c) The Author(s). 2018 Open Access This article is distributed under the terms of the Creative Commons Attribution 4.0 International License (http://creativecommons.org/licenses/by/4.0/), which permits unrestricted use, distribution, and reproduction in any medium, provided you give appropriate credit to the original author(s) and the source, provide a link to the Creative Commons license, and indicate if changes were made. The Creative Commons Public Domain Dedication waiver (http://creativecommons.org/publicdomain/zero/1.0/) applies to the data made available in this article, unless otherwise stated. 


\section{Background}

Following the quick accumulation of large-scale genome, transcriptome and other omics data, some studies or approaches integrating multiple omics data into pathway analysis have been reported [1-4]. Mass-spectrometry -based proteomics provides insights into cell-type protein expression patterns, post-translational modifications (PTMs) and protein-protein interactions [5-7]. As the most common PTMs, up to $30 \%$ of all human proteins may be modified by kinase activity (Phosphorylation), and kinases are known to regulate the majority of cellular signal pathways. To date, how to integrate the information of protein expression, PTMs and protein interactions in pathway analysis is still a big challenge.

Signal pathways describe a group of molecular in a cell that work together to control one or more cell functions, such as cell division or cell death. Pathway analysis gives an insight into the underlying mechanism in a given condition and makes it more explanatory in comparison with the studies at individual gene or protein level. Pathway analysis methods include gene set analysis and topology-based analysis. Gene set methods only consider the set of genes/proteins in the pathways while the topology-based methods use both genes/proteins and the interactions among them. Gene set methods consist of Over-Representation Analysis (ORA) based on the Hypergeometric test or Fisher exact test [8,9] and Functional Class Score (FCS) based on ranked gene list and Kolmogorov-Smirnov (K-S) test [10]. The ORA only considers the differentially-expressed (DE) genes and the representative tools of ORA include DAVID [11], Onto-Expression [9], GenMAPP [12], GOMiner [13], GOstat [14] and so on. FCS considers the position of all genes in the ranked list, which is produced by a selected statistical test for differential expression, such as Gene Set Enrichment Analysis (GSEA) [15], Gene Set Analysis (GSA) [16] and so on. Topology-based pathway analysis integrate both changes in expression level and in topology of protein/gene interaction network, which includes Signal pathway impact analysis (SPIA) [17] and Bayesian Pathway Analysis (BPA) [18]. In SPIA, the score of the pathway is based on the impact analysis consisting of two types of evidence. One is the over-representation of $\mathrm{DE}$ genes in a given pathway and the other is the abnormal perturbation of that pathway, which is measured by propagating expression changes across the pathway topology.

In this work, we tried to integrate proteomic and phosphoproteomic data in pathway analysis in breast cancer and its subtypes. The results showed that integrating protein and phosphorylation differential expression with the network-topology based method can identify the target pathways more accurately. What's more, we also identified the top ranked pathways in four subtypes of breast cancer specifically.

\section{Methods}

\section{Proteomics data and preprocessing}

The proteomic and phosphoproteomic data of breast cancer in this study included 77 tumor samples and 3 normal breast tissue samples, which were downloaded from Clinical Proteomic Tumor Analysis Consortium (CPTAC). The process of quality control and normalization for both the proteomic and phosphoproteomic data was presented in Mertin et al.'s work [5]. As the result, 12,553 proteins (10,062 genes) and 33,239 phosphosites with their relative abundances quantified across tumors were used in this work. The missing value in the data matrix was filled with the minimum value.

\section{Integrating proteomic and phosphoproteomic data}

Since ORA, GSEA and SPIA are the representatives of three kinds of pathway analysis, which are OverRepresentation analysis, Functional Class Score and topology-based pathway analysis, we used these three strategies to do pathway analysis. We used $\mathrm{R}$ package 'HTSanalyzeR' [19] to do ORA, GSEA pathway analysis and another $R$ package 'SPIA' [17] to do SPIA pathway analysis. $P$-values for pathway analysis resulting from the permutation $(n=2000)$ were provided in Additional File 1: Table S1.

Different methods of pathway analysis require different input data. For ORA, the input file is the list of DE proteins/modifications or the intersection of the DE protein and phosphoprotein as an integration (Student's t-test, with $\mathrm{BH}$-adjusted $p<0.05)$. The input file for GSEA method in our study was the list of all proteins/phosphoproteins with fold change between the case and control. We summed up and sorted the fold changes for the overlapping proteins in the protein expression and phosphorylation profiles as the integrated information for GSEA. As for SPIA, the input files consisted of the topology of the pathways downloaded from KEGG database and the DE proteins with their fold change. The topology changes of the pathways could be calculated by the 'SPIA' $R$ package. The input for SPIA was the intersection list of the DE proteins and DE phosphoproteins with the sum of their fold change.

\section{Performance evaluation}

For the performance evaluation of pathway analysis, a widely used validation method is using the ranks of the target pathways in disease that have been validated or curated in publication, topper rank is better. This method is proposed in PADOG [20] and used in other studies of pathway analysis methods comparison [21, 22].

We manually selected twelve breast cancer related TPs from literatures. Most of TPs are mentioned in the work about comprehensive molecular portraits of human breast tumors $[23,24]$ and the others are also 
widely accepted. The TPs and their references were listed in Table 1.

\section{Results}

The workflow of integrating proteomic and phosphoproteomic data to perform pathway analysis was shown in Fig. 1. Firstly, integrating information from proteomic and phosphoproteomic data were used as the input of pathway analysis. Then, we processed ORA, GSEA and SPIA pathway analysis on the integrated information. Finally, the methods were evaluated by the ranks of the TPs. In our study, we identified $2337 \mathrm{DE}$ proteins and 3973 DE phosphoproteins respectively. The intersection of the two lists were 641 proteins.

\section{Performance evaluation of pathway analysis with protein expression and/or phosphorylation profiles}

To assess the integrating strategies in pathway ranking with proteomics data, we compared the ranks of TPs in three kinds of pathway analysis methods with integrated information, including protein expression and phosphorylation datasets separately. Fig. 2 showed the box plots of normalized ranks in the range of 1 to 100 (the lower, the better). It could be concluded from the figure that all the pathway analysis methods performed better using the integrated data than using single information. Especially, topology-based pathway strategy introduced in SPIA performed best as the median rank of rankings for all the TPs was lower than any other methods.

Besides the TPs, we found nineteen pathways appearing in the overlap of the top 50 pathway ranking lists of three kinds of pathway analysis methods with integrated information, such as Fanconi anemia pathway, GABAergic synapse (as shown in Table 2). Although these pathways are not validated, as well as TPs to be

Table 1 The target pathways for breast cancer

\begin{tabular}{lll}
\hline KEGG ID & Pathway name & Reference \\
\hline hsa04014 & Ras signaling pathway & {$[24]$} \\
hsa04151 & PI3K-Akt signaling pathway & {$[23]$} \\
hsa04010 & MAPK signaling pathway & {$[23]$} \\
hsa04150 & mTOR signaling pathway & {$[45,47,49]$} \\
hsa04310 & Wht signaling pathway & {$[23]$} \\
hsa04115 & p53 signaling pathway & {$[23,33]$} \\
hsa01521 & EGFR tyrosine kinase inhibitor resistance & {$[23]$} \\
hsa04012 & ErbB signaling pathway & {$[23]$} \\
hsa04510 & Focal adhesion & {$[34,35]$} \\
hsa04350 & TGF-beta signaling pathway & {$[60]$} \\
hsa04110 & Cell cycle & {$[24]$} \\
hsa05200 & Pathways in cancer & {$[23]$} \\
\hline
\end{tabular}

related to breast cancer, there are still researches indicated the correlation with breast cancer. For example, Fanconi anemia pathway is closed linked to breast and ovarian cancer susceptibility gene BRCA1 [25, 26]. Abnormal GABA expression or GABAergic participation has been described in primary colon, gastric, ovarian, pancreatic, and breast cancers [27], while GABA and GABAergic participation are involved in GABAergic synapse [28]. What's more, it has been reported that morphine can stimulate angiogenesis by activating proangiogenic and survival-promoting signaling and promote breast tumor growth [29].

\section{Pathway rankings in subtypes of breast cancer}

The subtypes of breast cancer, which consist of Luminal A, Luminal B, Basal and HER2-enriched $[23,30]$, are various in prognosis and require distinct treatment [24, 31]. Genomic, transcriptomic, and proteomic analyses of the breast cancer also reveal subtypes would differ in pathway activity [32]. If the specific pathways and the underlying mechanism of each subtype are identified, more precision treatments can be applied. Based on the performance evaluation of different pathway analysis, we analyzed and ranked the perturbed pathways for each subtype by integrating protein expression and modification profiles using the network-topology based approach. The results showed ranking of the perturbed TPs in four subtypes (Additional File 2: Figure S1). Some pathways, like cell cycle and pathway in cancer, were among top10 rankings in all of subtypes. The ranks of other TPs were different among the subtypes though they all play important roles in four subtypes. We selected representative top-ranked pathways in each subtype and display them in Fig. 3.

As shown in Fig. 3a, p53 pathway ranked lowest in the Basal-like breast cancer type and ranked lower in Luminal A than in Luminal B. It is reported that TP53 are the most recurrently mutated genes in breast cancer, with frequency of $84 \%$ in Basal-like tumors [23] and p53 pathway remains largely intact in Luminal A cancers but is often inactivated in the more aggressive Luminal B cancers [33].

In accordance with previous research, expression levels of Focal adhesion kinase (FAK/PTK2) are correlated strongly with poor tumor differentiation and significantly associated with HER2 overexpression in breast cancer [34]. The highest level of FAK (Y861) and the lowest level of epidermal growth factor receptor 2 (HER2) activity can be observed in MDA-361 cells (ER+/HER2+ cell) [35]. As FAK is the important role in the Focal adhesion pathway, we can infer that the activation of the Focal adhesion pathway was negative correlated with the expression of HER2. The rank 


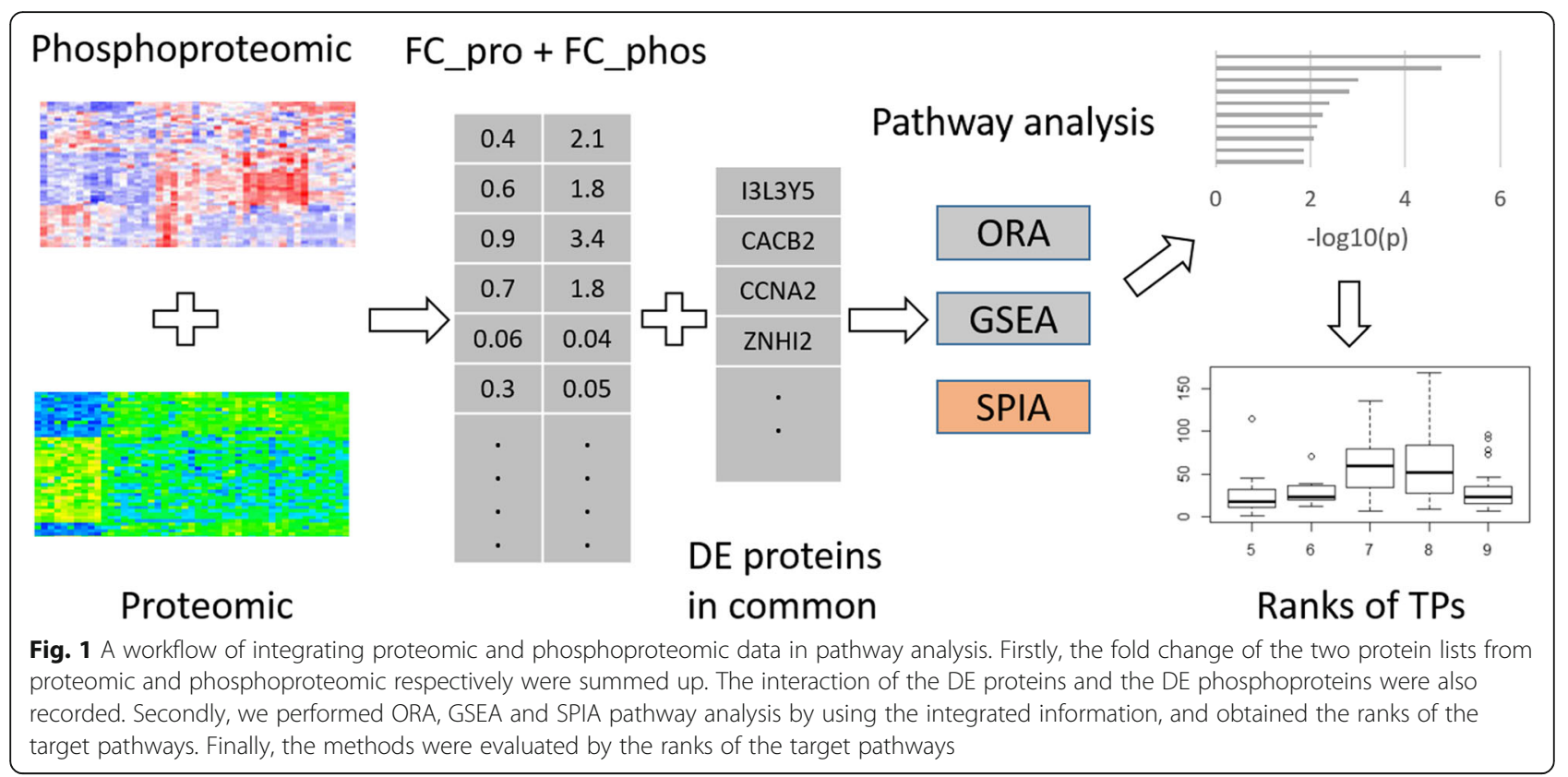

of Focal adhesion pathway was lower in HER2subtypes (Luminal A and HER2) than HER+ subtypes (Luminal B and Basal), as shown in Fig. 3b.

$\mathrm{PI} 3 \mathrm{~K} / \mathrm{AKT} / \mathrm{mTOR}$ pathway is a key intracellular signaling system that drives cellular growth and survival.
Hyperactivation of this pathway is implicated in the tumorigenesis of ER+ breast cancer [36-45]. Besides, the pathway is also important in Triple-negative breast cancer [46] and HER2-overexpressing breast cancer [47]. Preclinical studies indicate that inhibitors

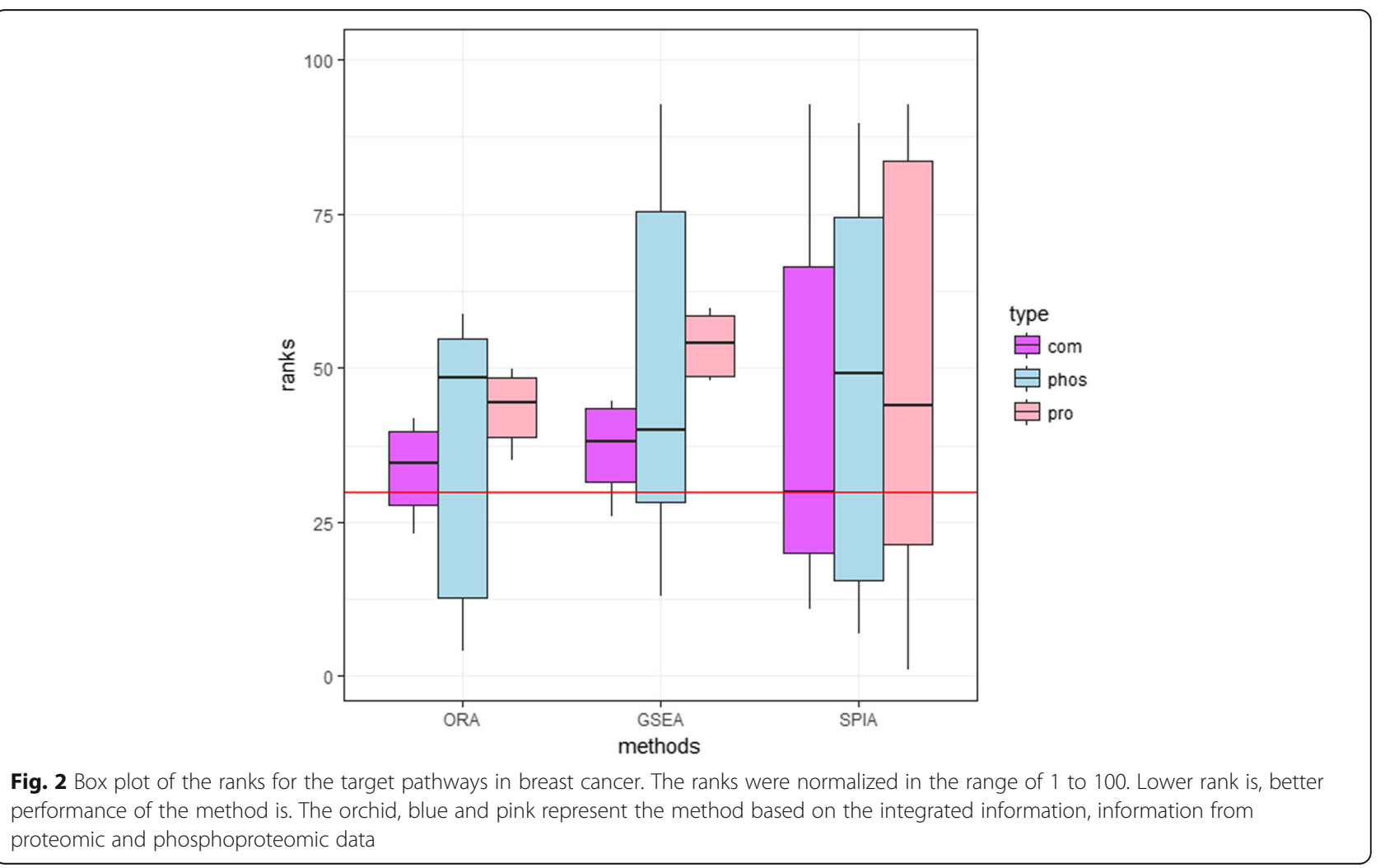


Table 2 The overlap of top 50 ranking pathways in three methods with integrated information

\begin{tabular}{ll}
\hline KEGG ID & Pathway name \\
\hline hsa03460 & Fanconi anemia pathway \\
hsa04020 & Calcium signaling pathway \\
hsa04024 & cAMP signaling pathway \\
hsa04060 & Cytokine-cytokine receptor interaction \\
hsa04261 & Adrenergic signaling in cardiomyocytes \\
hsa04340 & Hedgehog signaling pathway \\
hsa04710 & Circadian rhythm \\
hsa04713 & Circadian entrainment \\
hsa04723 & Retrograde endocannabinoid signaling \\
hsa04724 & Glutamatergic synapse \\
hsa04725 & Cholinergic synapse \\
hsa04727 & GABAergic synapse \\
hsa04912 & GnRH signaling pathway \\
hsa04914 & Progesterone-mediated oocyte maturation \\
hsa05020 & Prion diseases \\
hsa05032 & Morphine addiction \\
hsa05166 & HTLV-l infection \\
hsa05216 & Thyroid cancer \\
hsa05217 & Basal cell carcinoma \\
\hline
\end{tabular}

of the pathway can act synergistically with trastuzumab in resistant cells [48].

Many studies have established that mTOR pathway has tightly interaction with PI3K-AKT and MAPK signaling pathways. Inhibition of mTORC1, an important part of mTOR pathway, leads to MAPK pathway activation through a PI3K-dependent feedback in human cancer [49]. It can be verified by the ranks of these pathways in four breast subtypes, the low rank of mTOR pathway corresponded to the high rank of PI3K-Akt signaling pathway (Fig. 3c and d). Luminaltype cells might use the MEK-ERK pathway to a lesser extent and seem to be more dependent on the PI3K pathway, shown by the preferential occurrence of PI3K mutations in this subtype [10]. As show in Fig. 3d, PI3K-Akt signaling pathway in Luminal subtype ranked higher than the other two subtypes.

We also took a look at the top 20 ranked pathways for each subtype of breast cancer. There were 7 common pathways among the four subtypes. Besides two TPs cell cycle and pathways in cancer, the other common pathways have been reported to be related with breast cancer pathways which consist of Fanconi anemia pathway [50], Progesterone-mediated oocyte maturation [51, 52], Axon guidance [53], Basal cell carcinoma [54] and Thyroid cancer [55, 56]. As shown in Fig. 4, some pathways were specifically ranked in top 20 for Basal, HER2, Luminal A and Luminal B respectively. This result indicated that the subtypes share some common molecular mechanisms during carcinogenesis and development, but the differences between them also exist. For example, as we mentioned above, p53 pathway is significantly perturbed in Basal-like subtype but it also play key role in the other three subtypes [23, 57]. Notch pathway in Luminal breast cancer is activated more than in Basal and HER2 subtypes [58, 59].

\section{Discussion}

Expression and modification describe the in vivo changes of proteins in cancer proteome at different views. The pathway analysis based on the information at single level, such as protein expression or protein phosphorylation alone, often brings high risk of both false positive and false negative due to technological limitations. To the best of our knowledge, the integration proteomic and phosphoproteomic data in pathway analysis in cancer has not been evaluated and reported. In this study, the pathway analysis was performed and compared using the integration of proteomic and phosphoproteomic data in CPTAC's breast cancer dataset. Moreover we tried to find the different patterns in pathway ranking among the subtypes.

Our results suggested that both differential expression of proteins and phosphorylation were useful for identifying the important pathways in cancer or cancer subtypes. Furthermore, the integration of protein expression and modification profiles could provide more comprehensive information and rank TPs more accurately. Although the ranking lists of three kinds of pathway analysis were different, some consistent results were observed since the expression change of proteins and phosphoproteins are used in all of strategies. While the GSEA requires the fold change of all proteins, it has more complete information reflecting the expression profile. SPIA needs the topology information of the pathways in addition, which can provide detailed influence between the nodes of pathways.

We also tested the performance using the union of DE proteins and phosphoproteins information in pathway ranking, but poor accuracy was obtained. It's possibly because of too much noise in individual omics data. In order to control the risk of false positive, the intersection of the DE proteins or DE PTMs were used as input in this study that might be too conservative. Because only one dataset was tested here, for some new pathways in top ranking list, more independent proteomics datasets in cancer need to be processed and validated in the future. 


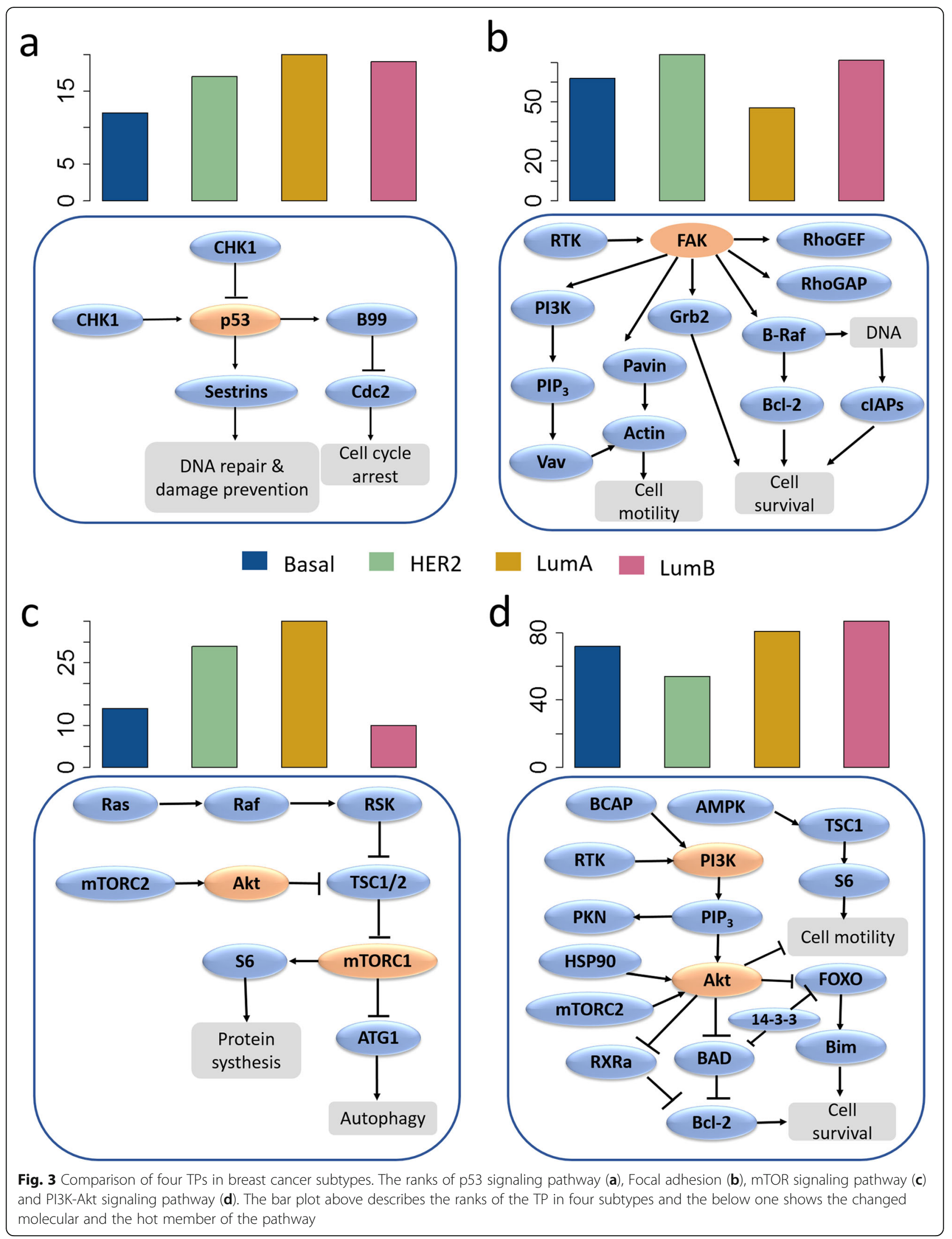




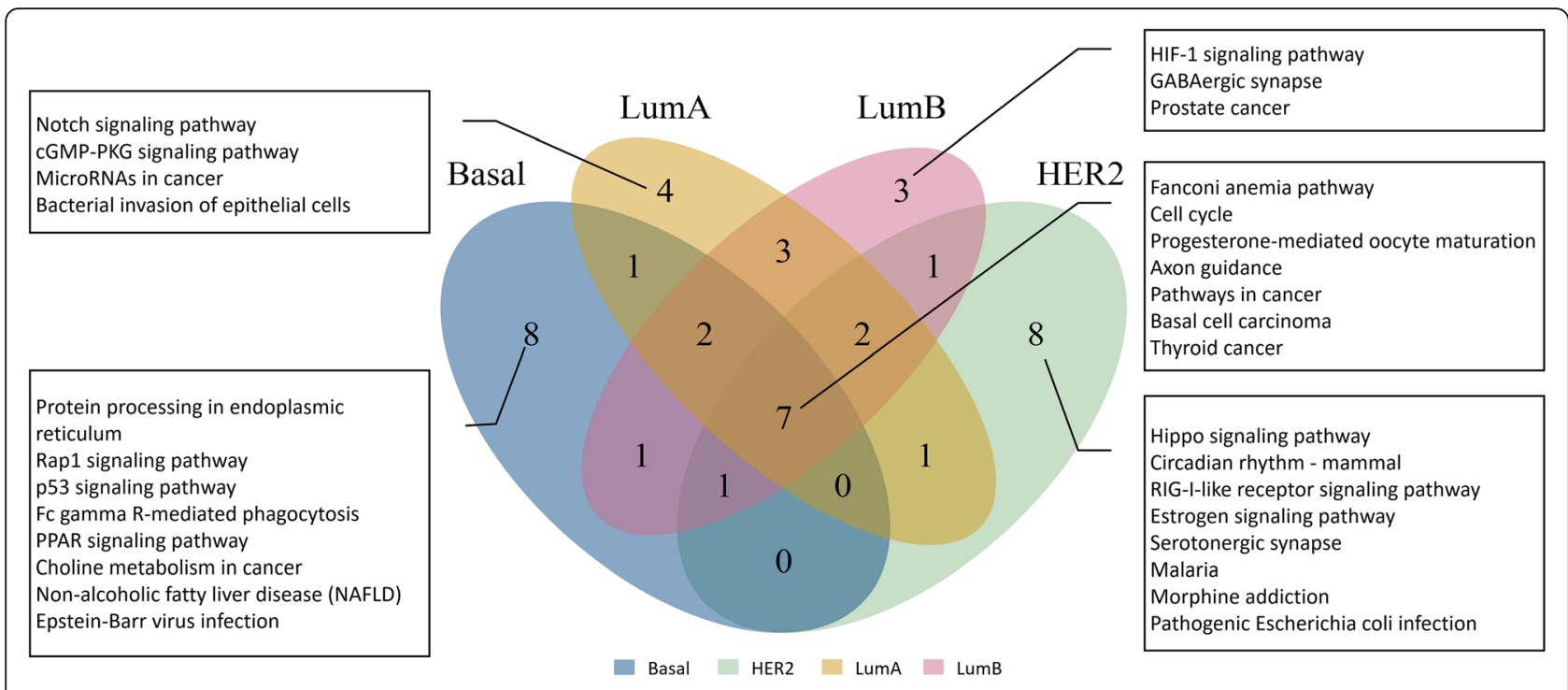

Fig. 4 The Venn diagram of top 20 ranking pathways for four subtypes. The top 20 pathways were ranked by the SPIA method with integrated information

\section{Conclusions}

Integrative pathway analysis by combing the information from protein expression, protein modification and the topology of protein interaction network is more efficient way to identify key pathway in breast cancer. Pathway ranking in certain subgroup of patients can provide insight into the specific mechanisms and be helpful for the precision medicine for each subtype.

\section{Additional files}

Additional file 1: Table S1. The results of different pathway ranking methods. (XLSX $89 \mathrm{~kb}$ )

Additional file 2: Figure S1. Ranks of TPs in subtypes of breast cancer. (DOCX $17 \mathrm{~kb})$

\section{Abbreviations}

BPA: Bayesian Pathway Analysis; CPTAC: Clinical Proteomic Tumor Analysis Consortium; DE: Differentially expressed; FAK: Focal adhesion kinase; FCS: Functional Class Score; GSA: Gene Set Analysis; GSEA: Gene Set Enrichment Analysis; K-S: Kolmogorov-Smirnov; ORA: Over-Representation Analysis; PTMs: Post-translational modifications; SPIA: Signal pathway impact analysis; TPs: Target pathways

\section{Acknowledgements}

We thank the High Performance Computing Center (HPCC) at Shanghai Jiao Tong University for the computation.

\section{Funding}

The work and the publication of this article were sponsored by grants from the National Natural Science Foundation of China (31271416).

\section{Availability of data and materials}

The datasets used in our study were downloaded from the publicly available databases mentioned in the text. The source code is available from the corresponding author on reasonable request.

\section{About this supplement}

This article has been published as part of BMC Systems Biology Volume 12 Supplement 8, 2018: Selected articles from the International Conference on Intelligent Biology and Medicine (ICIBM) 2018: systems biology. The full contents of the supplement are available online at https://bmcsystbiol.biomedcentral.c om/articles/supplements/volume-12-supplement-8.

\section{Authors' contributions}

JR worked on the method, experiment and analyses. BW designed the Figures. $J L$ contributed to the experiment and writing of the manuscript. All authors read and approved the final manuscript.

Ethics approval and consent to participate

Not applicable.

\section{Consent for publication}

Not applicable.

\section{Competing interests}

The authors declare that they have no competing interests.

\section{Publisher's Note}

Springer Nature remains neutral with regard to jurisdictional claims in published maps and institutional affiliations.

Published: 21 December 2018

\section{References}

1. Jia P, Liu Y, Zhao Z. Integrative pathway analysis of genome-wide association studies and gene expression data in prostate cancer. BMC Syst Biol. 2012;6(Suppl 3):S13. https://doi.org/10.1186/1752-0509-6-S3-S13.

2. Kamburov A, Cavill R, Ebbels TM, Herwig R, Keun HC. Integrated pathway-level analysis of transcriptomics and metabolomics data with IMPaLA. Bioinformatics. 2011;27(20):2917-8. https://doi.org/10.1093/bioinformatics/btr499.

3. Shen K, Tseng GC. Meta-analysis for pathway enrichment analysis when combining multiple genomic studies. Bioinformatics. 2010;26(10):1316-23. https://doi.org/10.1093/bioinformatics/btq148.

4. Sun $\mathrm{H}$, Wang $\mathrm{H}$, Zhu R, Tang $\mathrm{K}$, Gong Q, Cui J, et al. iPEAP: integrating multiple omics and genetic data for pathway enrichment analysis. Bioinformatics. 2014; 30(5):737-9. https://doi.org/10.1093/bioinformatics/btt576.

5. Mertins $P$, Mani DR, Ruggles KV, Gillette MA, Clauser KR, Wang P, et al. Proteogenomics connects somatic mutations to signalling in breast cancer. Nature. 2016;534(7605):55-62. https://doi.org/10.1038/nature18003. 
6. Zhang H, Liu T, Zhang Z, Payne SH, Zhang B, McDermott JE, et al. Integrated Proteogenomic characterization of human high-grade serous ovarian Cancer. Cell. 2016;166(3):755-65. https://doi.org/10.1016/j.cell.2016.05.069.

7. Wilhelm M, Schlegl J, Hahne H, Gholami AM, Lieberenz M, Savitski MM, et al. Mass-spectrometry-based draft of the human proteome. Nature. 2014; 509(7502):582. https://doi.org/10.1038/nature13319.

8. Draghici S. Statistical intelligence: effective analysis of high-density microarray data. Drug Discov Today. 2002;7(11):S55-63. https://doi.org/10. 1016/S1359-6446(02)02292-4

9. Khatri P, Draghici S, Ostermeier GC, Krawetz SA. Profiling gene expression using onto-express. Genomics. 2002;79(2):266-70. https://doi.org/10.1006/ geno.2002.6698.

10. Ackermann M, Strimmer K. A general modular framework for gene set enrichment analysis. BMC Bioinformatics. 2009;10:47. https://doi.org/10.1186/ 1471-2105-10-47.

11. Dennis G Jr, Sherman BT, Hosack DA, Yang J, Gao W, Lane HC, et al. DAVID: database for annotation, visualization, and integrated discovery. Genome Biol. 2003;4(5):P3. https://doi.org/10.1186/gb-2003-4-5-p3.

12. Dahlquist KD, Salomonis N, Vranizan K, Lawlor SC, Conklin BR. GenMAPP, a new tool for viewing and analyzing microarray data on biological pathways. Nat Genet. 2002:31(1):19. https://doi.org/10.1038/ng0502-19.

13. Zeeberg BR, Feng W, Wang G, Wang MD, Fojo AT, Sunshine M, et al. GoMiner: a resource for biological interpretation of genomic and proteomic data. Genome Biol. 2003;4(4):R28. https://doi.org/10.1186/gb-2003-4-4-r28.

14. Beißbarth T, Speed TP. GOstat: find statistically overrepresented gene ontologies within a group of genes. Bioinformatics. 2004;20(9):1464-5. https://doi.org/10.1093/bioinformatics/bth088.

15. Subramanian A, Tamayo P, Mootha VK, Mukherjee S, Ebert BL, Gillette MA, et al. Gene set enrichment analysis: a knowledge-based approach for interpreting genome-wide expression profiles. Proc Natl Acad Sci. 2005; 102(43):15545-50.

16. Efron B, Tibshirani R. On testing the significance of sets of genes. The annals of applied statistics. 2007;1:107-29. https://doi.org/10.1214/07-AOAS101.

17. Tarca AL, Draghici S, Khatri P, Hassan SS, Mittal P, Kim JS, et al. A novel signaling pathway impact analysis. Bioinformatics. 2009;25(1):75-82. https:// doi.org/10.1093/bioinformatics/btn577.

18. Korucuoglu M, Isci S, Ozgur A, Otu HH. Bayesian pathway analysis of cancer microarray data. PLoS One. 2014;9(7):e102803. https://doi.org/10.1371/ journal.pone.0102803.

19. Wang X, Terfve C, Rose JC, Markowetz F. HTSanalyzeR: an R/Bioconductor package for integrated network analysis of high-throughput screens. Bioinformatics. 2011;27(6):879-80. https:/doi.org/10.1093/bioinformatics/btr028.

20. Tarca AL, Draghici S, Bhatti G, Romero R. Down-weighting overlapping genes improves gene set analysis. BMC Bioinformatics. 2012;13:136. https:// doi.org/10.1186/1471-2105-13-136.

21. Bokanizad B, Tagett R, Ansari S, Helmi BH, Draghici S. SPATIAL: a systemlevel PAThway impact AnaLysis approach. Nucleic Acids Res. 2016;44(11): 5034-44. https://doi.org/10.1093/nar/gkw429.

22. Bayerlová M, Jung K, Kramer F, Klemm F, Bleckmann A, Beißbarth T. Comparative study on gene set and pathway topology-based enrichment methods. BMC bioinformatics. 2015;16(1):334.

23. Cancer Genome Atlas N. Comprehensive molecular portraits of human breast tumours. Nature. 2012:490(7418):61-70. https://doi.org/10.1038/nature11412.

24. Perou CM, Sorlie T, Eisen MB, van de Rijn M, Jeffrey SS, Rees CA, et al. Molecular portraits of human breast tumours. Nature. 2000;406(6797):74752. https://doi.org/10.1038/35021093.

25. Kennedy RD, D'Andrea AD. The Fanconi Anemia/BRCA pathway: new faces in the crowd. Genes Dev. 2005;19(24):2925-40. https://doi.org/10.1101/gad.1370505.

26. Moynahan ME, Cui TY, Jasin M. Homology-directed dna repair, mitomycin-c resistance, and chromosome stability is restored with correction of a Brcal mutation. Cancer Res. 2001;61(12):4842-50.

27. Young SZ, Bordey A. GABA's control of stem and cancer cell proliferation in adult neural and peripheral niches. Physiology. 2009;24(3):171-85. https:// doi.org/10.1152/physiol.00002.2009.

28. Lancaster E, Dalmau J. Neuronal autoantigens-pathogenesis, associated disorders and antibody testing. Nat Rev Neurol. 2012;8(7):380. https://doi. org/10.1038/nrneurol.2012.99

29. Wolf C, Chenard M-P, de Grossouvre PD, Bellocq J-P, Chambon P, Basset P. Breast-Cancer--associated Stromelysin-3 gene is expressed in basal cell carcinoma and during cutaneous wound healing. J Investig Dermatol. 1992; 99(6):870-2. https://doi.org/10.1111/1523-1747.ep12614846.
30. Parker JS, Mullins M, Cheang MC, Leung S, Voduc D, Vickery T, et al. Supervised risk predictor of breast cancer based on intrinsic subtypes. J Clin Oncol. 2009;27(8):1160-7. https://doi.org/10.1200/JCO.2008.18.1370.

31. Eroles P, Bosch A, Perez-Fidalgo JA, Lluch A. Molecular biology in breast cancer: intrinsic subtypes and signaling pathways. Cancer Treat Rev. 2012; 38(6):698-707. https://doi.org/10.1016/j.ctrv.2011.11.005.

32. Heiser LM, Sadanandam A, Kuo WL, Benz SC, Goldstein TC, Ng S, et al. Subtype and pathway specific responses to anticancer compounds in breast cancer. Proc Natl Acad Sci U S A. 2012;109(8):2724-9.

33. Deisenroth C, Thorner AR, Enomoto T, Perou CM, Zhang Y. Mitochondrial Hep27 is a c-Myb target gene that inhibits Mdm2 and stabilizes p53. Mol Cell Biol. 2010;30(16):3981-93. https://doi.org/10.1128/ MCB.01284-09.

34. Schmitz KJ, Grabellus F, Callies R, Otterbach F, Wohlschlaeger J, Levkau B, et al. High expression of focal adhesion kinase (p125FAK) in node-negative breast cancer is related to overexpression of HER-2/neu and activated Akt kinase but does not predict outcome. Breast Cancer Res. 2005;7(2):R194-203.

35. Lazaro G, Smith C, Goddard L, Jordan N, McClelland R, Barrett-Lee P, et al. Targeting focal adhesion kinase in ER+/HER2+ breast cancer improves trastuzumab response. Endocr Relat Cancer. 2013;20(5):691-704. https://doi. org/10.1530/ERC-13-0019.

36. Perez-Tenorio G, Alkhori L, Olsson B, Waltersson MA, Nordenskjold B, Rutqvist $L E$, et al. PIK3CA mutations and PTEN loss correlate with similar prognostic factors and are not mutually exclusive in breast cancer. Clin Cancer Res. 2007; 13(12):3577-84. https:/doi.org/10.1158/1078-0432.CCR-06-1609.

37. Stemke-Hale K, Gonzalez-Angulo AM, Lluch A, Neve RM, Kuo WL, Davies M, et al. An integrative genomic and proteomic analysis of PIK3CA, PTEN, and AKT mutations in breast cancer. Cancer Res. 2008;68(15):6084-91. https:// doi.org/10.1158/0008-5472.CAN-07-6854.

38. Ellis MJ, Lin L, Crowder R, Tao Y, Hoog J, Snider J, et al. Phosphatidyl-inositol-3kinase alpha catalytic subunit mutation and response to neoadjuvant endocrine therapy for estrogen receptor positive breast cancer. Breast Cancer Res Treat. 2010;119(2):379-90. https://doi.org/10.1007/s10549-009-0575-y.

39. Campbell IG, Russell SE, Choong DY, Montgomery KG, Ciavarella ML, Hooi $\mathrm{CS}$, et al. Mutation of the PIK3CA gene in ovarian and breast cancer. Cancer Res. 2004:64(21):7678-81. https://doi.org/10.1158/0008-5472.CAN-04-2933.

40. Gonzalez-Angulo AM, Ferrer-Lozano J, Stemke-Hale K, Sahin A, Liu S, Barrera $J A$, et al. PI3K pathway mutations and PTEN levels in primary and metastatic breast cancer. Mol Cancer Ther. 2011;10(6):1093-101. https://doi.org/10. 1158/1535-7163.MCT-10-1089.

41. Samuels Y, Wang Z, Bardelli A, Silliman N, Ptak J, Szabo S, et al. High frequency of mutations of the PIK3CA gene in human cancers. Science. 2004;304(5670):554. https://doi.org/10.1126/science.1096502.

42. Fu P, Ibusuki M, Yamamoto Y, Hayashi M, Murakami K, Zheng S, et al. Insulin-like growth factor-1 receptor gene expression is associated with survival in breast cancer: a comprehensive analysis of gene copy number, mRNA and protein expression. Breast Cancer Res Treat. 2011:130(1):307-17. https://doi.org/10.1007/s10549-011-1605-0.

43. Law JH, Habibi G, Hu K, Masoudi H, Wang MY, Stratford AL, et al. Phosphorylated insulin-like growth factor-i/insulin receptor is present in all breast cancer subtypes and is related to poor survival. Cancer Res. 2008: 68(24):10238-46. https://doi.org/10.1158/0008-5472.CAN-08-2755.

44. Saal LH, Johansson P, Holm K, Gruvberger-Saal SK, She QB, Maurer M, et al. Poor prognosis in carcinoma is associated with a gene expression signature of aberrant PTEN tumor suppressor pathway activity. Proc Natl Acad Sci U S A. 2007:104(18):7564-9.

45. Ciruelos Gil EM. Targeting the PI3K/AKT/mTOR pathway in estrogen receptor-positive breast cancer. Cancer Treat Rev. 2014;40(7):862-71. https:// doi.org/10.1016/j.ctrv.2014.03.004

46. Lehmann BD, Bauer JA, Chen X, Sanders ME, Chakravarthy AB, Shyr Y, et al. Identification of human triple-negative breast cancer subtypes and preclinical models for selection of targeted therapies. J Clin Invest. 2011; 121(7):2750-67. https://doi.org/10.1172/JCI45014.

47. Paplomata $\mathrm{E}_{1} \mathrm{O}$ 'Regan R. The PIJK/AKT/mTOR pathway in breast cancer: targets, trials and biomarkers. Ther Adv Med Oncol. 2014;6(4):154-66. https://doi.org/10.1177/1758834014530023.

48. Nahta R. Pharmacological strategies to overcome HER2 cross-talk and Trastuzumab resistance. Curr Med Chem. 2012;19(7):1065-75. https://doi. org/10.2174/092986712799320691.

49. Carracedo A, Ma L, Teruya-Feldstein J, Rojo F, Salmena L, Alimonti A, et al. Inhibition of MTORC1 leads to MAPK pathway activation through a PI3K- 
dependent feedback loop in human cancer. J Clin Invest. 2008;118(9):306574. https://doi.org/10.1172/JCl34739.

50. Jacquemont C, Taniguchi T. The Fanconi anemia pathway and ubiquitin. BMC Biochem. 2007;8(Suppl 1):S10. https://doi.org/10.1186/1471-2091-8-S1-S10.

51. Dressing GE, Thomas P. Identification of membrane progestin receptors in human breast cancer cell lines and biopsies and their potential involvement in breast cancer. Steroids. 2007;72(2):111-6. https://doi.org/10.1016/j.steroids. 2006.10.006.

52. Dressing GE, Alyea R, Pang $Y$, Thomas P. Membrane progesterone receptors (mPRs) mediate progestin induced antimorbidity in breast cancer cells and are expressed in human breast tumors. Horm Cancer. 2012;3(3):101-12. https://doi.org/10.1007/s12672-012-0106-X.

53. Harburg GC, Hinck L. Navigating breast cancer: axon guidance molecules as breast cancer tumor suppressors and oncogenes. J Mammary Gland Biol Neoplasia. 2011;16(3):257-70. https://doi.org/10.1007/s10911-011-9225-1.

54. Wolf C, Chenard MP, Durand de Grossouvre P, Bellocq JP, Chambon P, Basset P. Breast-cancer-associated stromelysin-3 gene is expressed in basal cell carcinoma and during cutaneous wound healing. J Invest Dermatol. 1992;99(6):870-2. https://doi.org/10.1111/1523-1747.ep12614846.

55. Liaw D, Marsh DJ, Li J, Dahia PL, Wang SI, Zheng Z, et al. Germline mutations of the PTEN gene in Cowden disease, an inherited breast and thyroid cancer syndrome. Nat Genet. 1997;16(1):64-7. https://doi.org/10. 1038/ng0597-64

56. Turken O, Narln Y, Demlrbas S, Onde ME, Sayan O, Kandemlr EG, et al. Breast cancer in association with thyroid disorders. Breast Cancer Res. 2003; 5(5):R110-3.

57. Carey LA, Perou CM, Livasy CA, Dressler LG, Cowan D, Conway K, et al. Race, breast cancer subtypes, and survival in the Carolina breast Cancer study. JAMA. 2006;295(21):2492-502. https://doi.org/10.1001/jama.295.21.2492.

58. Haughian JM, Pinto MP, Harrell JC, Bliesner BS, Joensuu KM, Dye WW, et al. Maintenance of hormone responsiveness in luminal breast cancers by suppression of notch. Proc Natl Acad Sci. 2012;109(8):2742-7.

59. Stylianou S, Clarke RB, Brennan K. Aberrant activation of notch signaling in human breast cancer. Cancer Res. 2006;66(3):1517-25. https://doi.org/10. 1158/0008-5472.CAN-05-3054.

60. Buck MB, Knabbe C. TGF-Beta signaling in breast Cancer. Ann N Y Acad Sci. 2006;1089(1):119-26.

Ready to submit your research? Choose BMC and benefit from:

- fast, convenient online submission

- thorough peer review by experienced researchers in your field

- rapid publication on acceptance

- support for research data, including large and complex data types

- gold Open Access which fosters wider collaboration and increased citations

- maximum visibility for your research: over $100 \mathrm{M}$ website views per year

At $\mathrm{BMC}$, research is always in progress.

Learn more biomedcentral.com/submissions 